\title{
Seasonal Contributions to the Climatic Variations Recorded in Tree Ring Deuterium/Hydrogen Data
}

\author{
Crayton J. YapP \\ Department of Geology, University of New Mexico, Albuquerque
}

SAMUEL EPSTEIN

Division of Geological and Planetary Sciences, California Institute of Technology, Pasadena

\begin{abstract}
Tree ring $\delta \mathrm{D}$ records do not always reflect variations in the average annual $\delta \mathrm{D}$ values of local precipitation, but may instead record changes in the $\delta \mathrm{D}$ values of seasonal components of precipitation. The $\delta \mathrm{D}$ values measured for tree ring sequences from the three trees in this study are correlated with variations in summer climatic conditions at each of the sites. The $\mathrm{D} / \mathrm{H}$ ratios in an aspen from Fairbanks, Alaska, correlate with summer temperatures in Fairbanks. An aspen which grew near Anchorage, Alaska, and a pine located near Seeley Lake, British Columbia, contain $\delta \mathrm{D}$ records which correlate with the amount of summer precipitation at their respective sites. The $\delta \mathrm{D}$ variations of the two Alaskan aspens are correlated for the five 5-year sample intervals which they have in common. It is emphasized that a correlation between tree ring $\delta \mathrm{D}$ variations and a local seasonal climatic parameter for a given tree does not imply that all trees in that area will exhibit similar correlations. The site and growth conditions of individual trees will probably determine what climatic signal is contained in the $D / H$ records of each.
\end{abstract}

\section{INTRODUCTION}

Stable hydrogen and oxygen isotope ratios in precipitation have been observed to vary on a seasonal basis at a single site [e.g., Siegenthaler and Oeschger, 1980], on a glacial to interglacial scale [Epstein et al., 1970; Dansgaard et al., 1971] and, in a comparatively systematic way, on a broad geographic scale [e.g., Friedman et al., 1964; Dansgaard, 1964]. In these instances the temporal and spatial variations in precipitation stable isotope ratios have been correlated with, or attributed to, variations in local temperature. Such observations appear to set the stage for the interpretation of variations of ancient meteoric water $\mathrm{D} / \mathrm{H}$ and/or ${ }^{18} \mathrm{O} /{ }^{16} \mathrm{O}$ ratios in terms of variations in continental paleotemperatures. Since direct preservation of precipitation in a resolvable chronology is only probable in the polar regions (glaciers, permafrost), it is generally necessary to seek proxy records of isotope variations in ancient continental precipitation.

Nonexchangeable hydrogen and oxygen in tree cellulose have been studied as a possible source of information on precipitation $\mathrm{D} / \mathrm{H}$ and ${ }^{18} \mathrm{O} /{ }^{16} \mathrm{O}$ variations. Gray and Thompson [1976], Epstein et al. [1977], and Burk and Stuiver [1981] have shown that the ${ }^{18} \mathrm{O} /{ }^{16} \mathrm{O}$ ratios of tree cellulose can vary in concert with the ${ }^{18} \mathrm{O} /{ }^{16} \mathrm{O}$ ratios of local precipitation and thus can provide information on local climatic variation. Epstein et al. [1976] and Yapp and Epstein [1982a] demonstrated that the $\mathrm{D} / \mathrm{H}$ ratio of carbon-bound hydrogen in tree cellulose generally reflects the $\mathrm{D} / \mathrm{H}$ ratio of the ambient meteoric water. Studies on whole wood tissue [Schiegl, 1974] and on nitrated tree cellulose [Epstein and Yapp, 1976; Yapp and Epstein, 1977, 1982b] have shown that tree D/H ratios can be correlated with variations in temperature on both a temporal and a spatial scale. The aforementioned hydrogen isotope studies have emphasized the correspondence between tree

Copyright 1985 by the American Geophysical Union.

Paper number 4D1528.

0148-0227/85/004D-1528\$05.00 cellulose $\mathrm{D} / \mathrm{H}$ variations and variations in local annual temperature.

However, there has been some indication that the $D / H$ ratios in tree cellulose are not always related to the $\mathrm{D} / \mathrm{H}$ ratios of local average annual precipitation. Epstein and Yapp [1976] noted that $\delta \mathrm{D}$ values from a Scots pine correlated better with winter temperature than with annual temperature. This suggested that winter precipitation was probably the dominant influence on the $\delta \mathrm{D}$ values of this Scots pine. Recently, Lawrence and White [1984] have found a correlation between $\delta \mathrm{D}$ values in tree rings and the amount of local summer precipitation at a site near the eastern coast of the United States in New York.

Twenty-five trees from a wide geographic range were analyzed for their D/H ratios [Yapp and Epstein, 1982b]. This survey of the large-scale geographic variability of tree $D / H$ ratios employed trees which were collected by a number of individuals. No guidelines about local site conditions were established for sample collection. Thus the trees represented a wide variety of "randomly" chosen, unstudied growth environments. Such "random" sampling might mimic the circumstance of the interpretation of $\mathrm{D} / \mathrm{H}$ data from ancient, buried wood samples which are themselves recovered by chance. As part of this survey, $\mathrm{D} / \mathrm{H}$ ratios within tree ring sequences were analyzed and compared to local instrumental temperature and precipitation data. It was found that $\mathrm{D} / \mathrm{H}$ variations within two aspens from Alaska and a pine from British Columbia correlated better with summer climatic parameters than with annual temperature. The $\mathrm{D} / \mathrm{H}$ data from these three trees are discussed in this paper.

\section{Samples and ANalytical Methods}

The aspens in this study grew near Fairbanks, Alaska, and Anchorage, Alaska (see Figure 1). The former was collected by B. Kamb from Chena Ridge near Fairbanks. Its chronology extends from A.D. 1951 to 1977 . Five samples each containing 5 years of growth rings were removed from the cross-sectional sample of the bole of the tree. A sample composed of the 


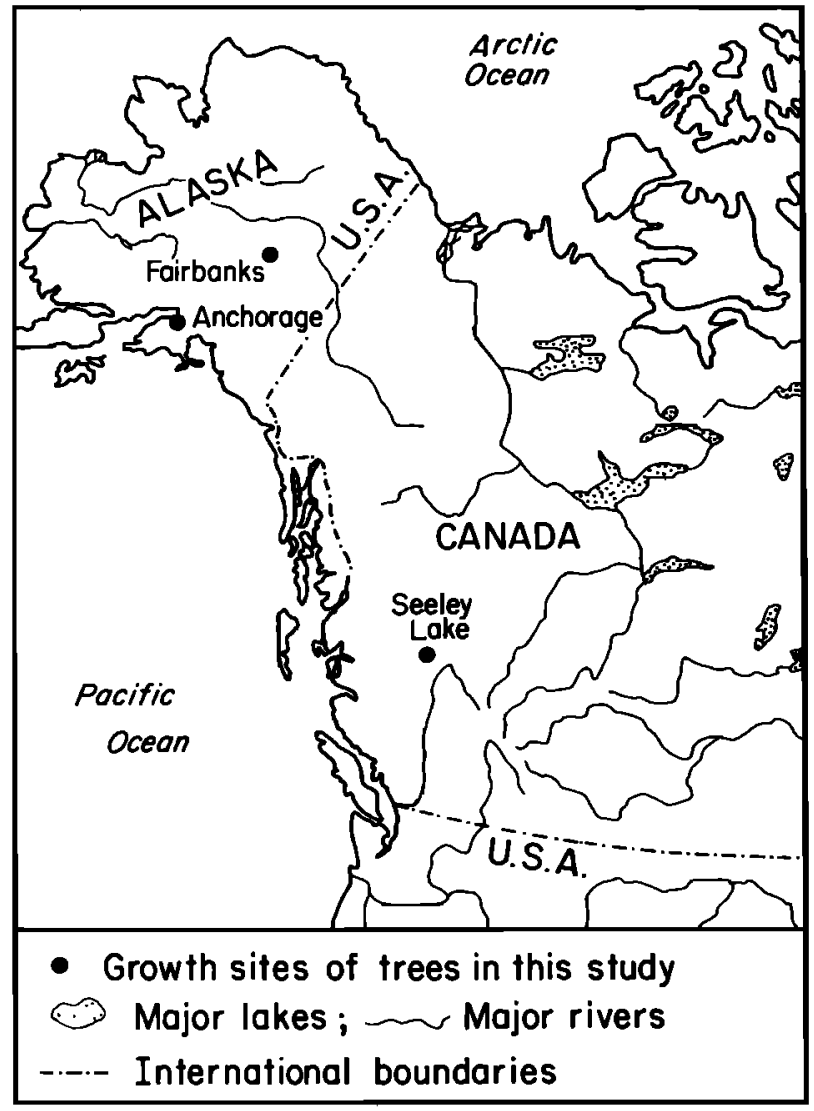

Fig. 1. Locations of the three trees employed in this study. All three areas are dominated by Pacific air masses in the summer months.

outermost 2 years of growth (1976-1977) was also collected. The aspen located near Anchorage, Alaska, was collected by $S$. Spearrow and grew about $150 \mathrm{~m}$ above the Knik River on the north side of West Twin Peak. A sequence of samples (each containing 5 years of growth) representing the interval A.D. 1936-1975 was removed from a cross section of wood from the bole of the tree. The pine from British Columbia, Canada, grew in the region of Seeley Lake about $100 \mathrm{~km}$ westnorthwest of Prince George, B.C. (Figure 1). The tree was collected by H. P. Taylor, Jr., and provided 5-year samples extending from 1896 to 1970.

The $\mathbf{D} / \mathrm{H}$ data reported here were obtained by the renitration method of DeNiro [1981] and Yapp and Epstein [1982a]. This method involves the combustion of nitrated tree cellulose to recover the carbon-bound hydrogen as water. The water is quantitatively converted to hydrogen gas over uranium metal at about $800^{\circ} \mathrm{C}$. The $\mathrm{H}_{2}$ yield is measured manometrically, and the hydrogen gas is measured for its $\mathrm{D} / \mathrm{H}$ ratio on a modified Nier-type mass spectrometer [McKinney et al., 1950]. The data are corrected for $\mathrm{H}_{3}{ }^{+}$, background, and valve leakage [Friedman, 1953; Craig, 1957] and are reported in the usual delta notation:

$$
\delta \mathrm{D}=\left[\frac{R \text { (sample) }}{R \text { (standard) }}-1\right] \times 1000 \%
$$

when $R=\mathrm{D} / \mathrm{H}$ and the standard is Standard Mean Ocean Water (SMOW) as defined by Craig [1961]. Overall analytical precision for the method is $\pm 2 \%$.
Results

\section{Alaskan Aspens}

The results of the $\mathrm{D} / \mathrm{H}$ analyses of the ring sequences from the two Alaskan aspens are presented in Figure 2. In both cases there is an almost monotonic increase in $\delta \mathrm{D}$ values from older to younger samples. The total $\delta \mathrm{D}$ range in the Fairbanks aspen is $28 \%$, while the total $\delta \mathrm{D}$ range of the Anchorage aspen is $29 \%$. Over the time interval that the tree samples have in common (1951-1975) the $\delta \mathrm{D}$ range of the Fairbanks aspen is $17 \%$, while that of the Anchorage aspen is $19 \%$. The $\delta D$ values of the Fairbanks aspen are about 18-20\% more negative than the corresponding $\delta \mathrm{D}$ values of the Anchorage aspen. Furthermore, the $\delta \mathrm{D}$ variations of the two aspens are correlated (Figure 3).

Instrumental meteorological data from Anchorage, Alaska, are available from 1941 to present, thus coinciding with all but the first 5 years of the tree ring $\delta \mathrm{D}$ record from the Anchorage aspen. Meteorological data from Fairbanks, Alaska, coincide with the entire $\delta \mathrm{D}$ record from the Fairbanks aspen.

If these trees have preserved $\delta \mathrm{D}$ variations that reflect the $\delta \mathrm{D}$ variations of average annual precipitation, there is an expectation that the tree $\delta \mathrm{D}$ values will correlate with the local average annual surface temperature [e.g., Dansgaard, 1964; Yapp and Epstein, 1982b]. A linear regression of the six Fairbanks $\delta \mathrm{D}$ values with local average annual temperature yields a correlation coefficient $r$ of 0.74 , while a similar regression of the seven Anchorage $\delta \mathrm{D}$ values with annual Anchorage temperature has an $r$ value of -0.01 . Thus there is no correspondence between the $\delta \mathrm{D}$ record of the Anchorage aspen and local annual temperature, while there appears to be some such relationship for the Fairbanks data.

\section{Pine From Seeley Lake, British Columbia}

The $\delta \mathrm{D}$ values from this pine are plotted in Figure 4 . The total $\delta \mathrm{D}$ range is $26 \%$. Over the entire length of the record

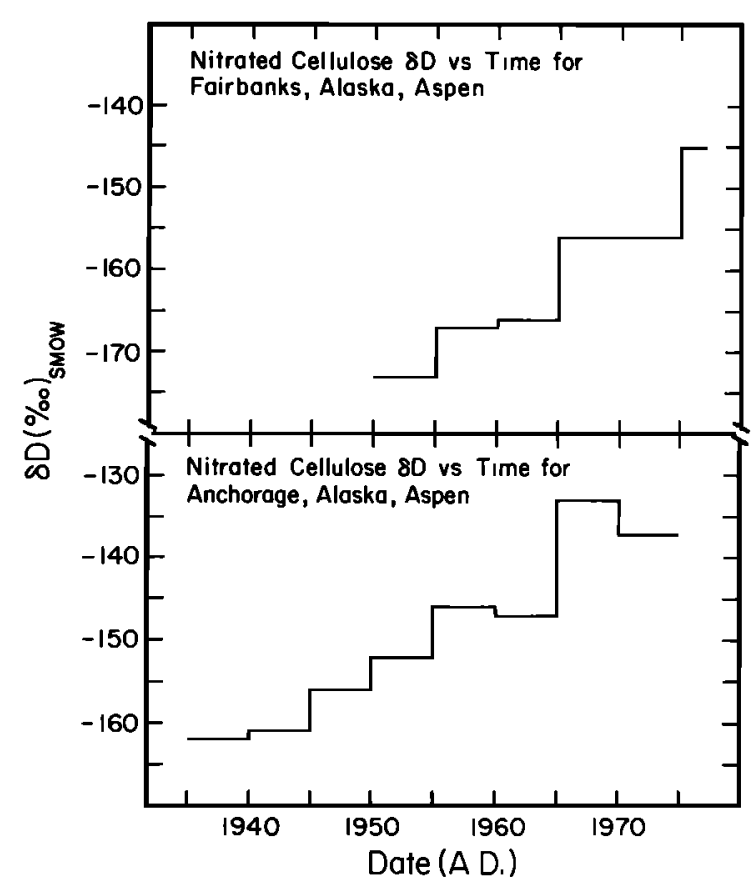

Fig. 2. The $\delta \mathrm{D}$ variations in the two Alaskan aspens with time. Note the monotonic increase in $\delta D$ from older to younger samples. 
there is no monotonic variation of $\delta \mathrm{D}$ values. In particular, there is no systematic trend to the $\delta \mathrm{D}$ values in the portion of the record from 1936 to 1970 . This is in contrast to the increase in $\delta \mathrm{D}$ values noted for the two Alaskan aspens within this interval. The nearest meteorological station is Prince George, British Columbia. Precipitation and temperature data have been recorded since 1916 . A regression of 11 tree ring $\delta D$ values against average annual temperature at Prince George yields a correlation coefficient of only -0.01 . Thus there is no relationship between tree $\delta \mathrm{D}$ values and annual temperature at these sites.

\section{Discussion}

\section{Alaskan Aspens}

Over $50 \%$ of the average annual precipitation in Anchorage, Alaska, falls in the summer months of June, July, August, and September [Hare and Hay, 1974]. Thus any climatic record preserved in the $\mathrm{D} / \mathrm{H}$ variations of this tree ring sequence could be that of summer conditions. A linear regression of the seven $\delta \mathrm{D}$ values with corresponding Anchorage "summer" temperatures (June, July, August, September) yields an $r$ value of 0.48 . For a summer defined as June, July, and August, $r$ is 0.56 , which is the maximum value of the correlation coefficient observed for any regressions of these $\delta \mathrm{D}$ values against temperature. The correlation of the Anchorage aspen $\delta \mathrm{D}$ values with local summer temperature is poor, but there is another important climatic variable that may bear on this discussion: the amount of summer precipitation.

Dansgaard [1964] observed that there is a negative correlation between monthly precipitation $\delta \mathrm{D}$ (and $\delta^{18} \mathrm{O}$ ) values and monthly precipitation amount in many tropical, oceanic islands. In addition, he noted a similar negative correspondence between isotope ratios and monthly precipitation amount in the summer records of several maritime, temperate, continental sites. As noted previously, Lawrence and White [1984] observed a correlation between tree ring $\delta \mathrm{D}$ values and amounts of summer precipitation. Their observations were made on individual rings of Eastern White Pine spanning a maximum interval from A.D. 1960 to 1980.

In the present work the sample intervals are 5 years. The summer precipitation amount $W_{s}$ is represented as the average monthly precipitation during the summer months in the

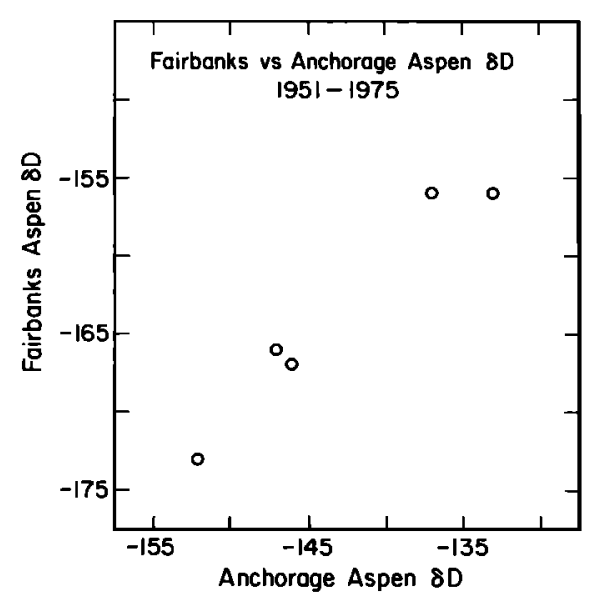

Fig. 3. Plot of the $\delta \mathrm{D}$ values of the Fairbanks aspen (FA) versus the corresponding $\delta \mathrm{D}$ values of the Anchorage aspen (AA). A linear regression of these data yields the equation $\delta \mathrm{D}_{\mathrm{FA}}=0.93 \delta \mathrm{D}_{\mathrm{AA}}-30$, with $r=0.98$.

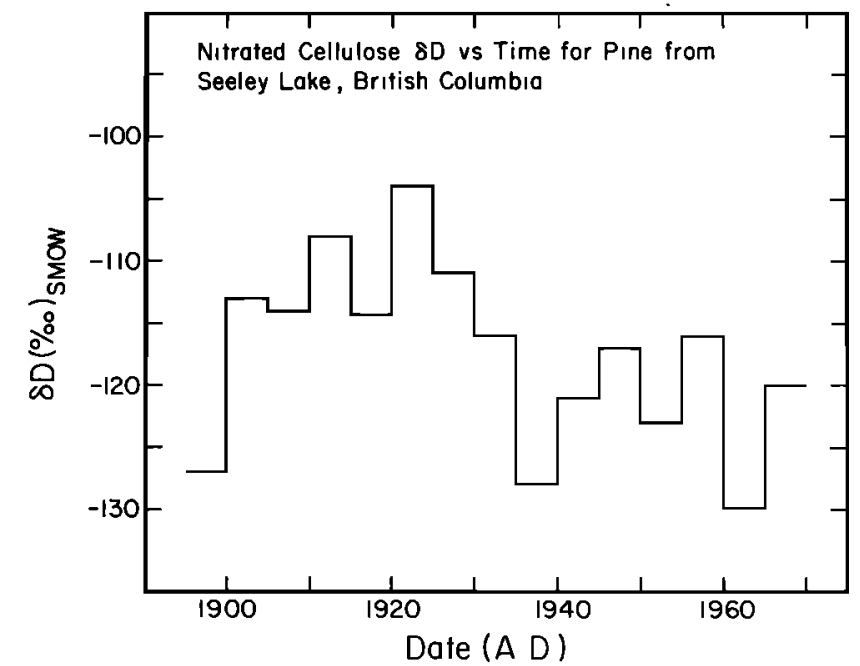

Fig. 4. Variations of the $\delta \mathrm{D}$ values from the Seeley Lake, British Columbia, pine versus time. There is no long-term $\delta \mathrm{D}$ trend in the overall sequence, but the $\delta \mathrm{D}$ variance is rather large.

5-year interval of interest. For summer defined as June, July, and August a regression of the aspen $\delta \mathrm{D}$ values against average monthly precipitation in Anchorage yields a correlation coefficient $r$ of -0.67 , while a regression of the data for summer defined as June, July, August, and September yields a value of -0.71 . The latter value is the optimal value of $r$ observed for any regression of the aspen $\delta \mathrm{D}$ data against precipitation amount. A plot of the aspen $\delta \mathrm{D}$ values versus the average monthly amount of summer precipitation recorded for Anchorage is shown in Figure 5 (summer defined as June, July, August, and September). The equation resulting from the linear regression of these data is

$$
\delta \mathrm{D}=-0.88 W_{s}-104
$$

where $W_{s}$ is the average monthly summer precipitation (in millimeters). Although there are only seven data points, the general correspondence between the tree $\delta \mathrm{D}$ values and the amount of summer precipitation (Figure 5) implies that (1) the tree has incorporated only (or predominantly) summer precipitation and (2) 5-year samples of the summer precipitation at Anchorage, Alaska, may meet, to a large degree, the conditions necessary for a so-called "amount effect" on $D / H$ ratios [Dansgaard, 1964; Yapp, 1982].

The correlation between the $\delta \mathrm{D}$ values of the five sample intervals common to the Fairbanks and Anchorage aspens (Figure 3) raises the possibility of a long-term, sympathetic variation in the precipitation-producing processes at these two sites during this 25 -year period. Furthermore, the $\delta \mathrm{D}$ correlation between the two trees suggests that the $\delta \mathrm{D}$ variations in the Fairbanks aspen may, like those in the Anchorage aspen, be more in response to summer climatic conditions than annual climate. This possibility is enhanced by the fact that nearly $60 \%$ of the total annual precipitation in Fairbanks falls in the summer months of June, July, August, and September.

The optimal correlation ceflicient calculated for a linear regression of the Fairbanks aspen $\delta D$ values against local summer precipitation amounts was only $\mathbf{- 0 . 4 6}$ (for summer defined as June, July, and August). However, an optimal $r$ value of 0.92 was determined for the correlation of the tree $\delta \mathrm{D}$ values with Fairbanks summer temperature when summer was defined as June, July, August, and September. A plot of these $\delta \mathrm{D}$ versus temperature data is shown in Figure 5. The best fit 


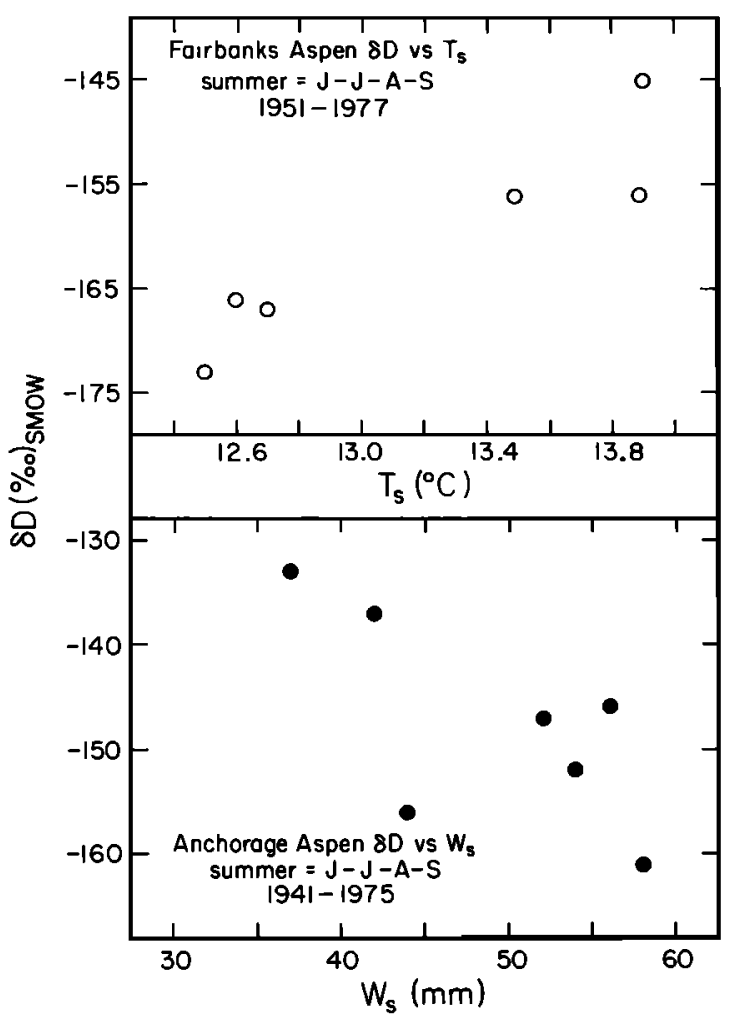

Fig. 5. The $\delta \mathrm{D}$ values of the Alaskan aspens versus local summer climatic parameters. For the Fairbanks aspen the best $\delta \mathrm{D}$ correlation was with local summer temperature, while for the Anchorage aspen, $\delta \mathrm{D}$ values correlated best with the monthly average amount of summer precipitation $\left(W_{s}\right)$. In both cases the optimal correlations were for summer defined as June, July, August, and September.

linear equation of these data is

$$
\delta \mathrm{D}=14.1 T_{s}-347
$$

where $T_{s}$ is the average summer temperature (in degrees Celsius).

The systematic deuterium depletion of the Fairbanks aspen compared to the Anchorage aspen (Figure 3) is characteristic of the deuterium depletion in precipitation observed between many coastal and interior sites [Friedman et al., 1964]. More negative values are to be expected for inland sites, because by the time an air mass reaches the inland site it will probably have cooled and lost some of its moisture as precipitation. Thus the moisture remaining to be precipitated at the inland site plus any moisture contributed locally by evaporation from the land will generally have more negative $\delta \mathrm{D}$ values than at the coastal location [Epstein and Mayeda, 1953; Dansgaard, 1964; Friedman et al., 1964; Rozanski et al., 1982]. This simple scenario is best approximated if precipitating air masses at the coastal and inland sites in question have followed a condensation trajectory from a single oceanic moisture source [e.g., Yapp and Epstein, 1977]. Pacific air masses predominate at Anchorage and Fairbanks in the summer months [Bryson and Hare, 1974], and the Gulf of Alaska is the principal source of moisture for summer precipitation [Benton and Estoque, 1954; Hare and Hay, 1974]. Consequently, the conditions necessary for a long-term sympathetic isotopic variation in summer precipitation may exist at Anchorage and Fairbanks.

The foregoing discussion is based on $\delta \mathrm{D}$ data which are relatively few in number and represent a brief span of time. Additional and older trees from each of these locations could provide a more satisfactory test of the apparent isotopic co- variance at the two sites. However, the existing data do suggest that such isotopic studies could be a powerful probe into large-scale precipitation-producing climatic processes.

\section{British Columbian Pine}

As noted previously, there is no correlation between the $\delta \mathrm{D}$ values of this pine and annual temperature as recorded at Prince George, British Columbia. This suggests that correlations between $\delta \mathrm{D}$ values and seasonal climatic variables should be sought. No correlation was observed between the $\delta \mathrm{D}$ values and winter temperature or winter precipitation at Prince George. Similarly, there is no correlation between the $\delta \mathrm{D}$ values and summer temperature. However, a comparison of "summer" precipitation amount with the pine tree $\delta \mathrm{D}$ values reveals an optimal correlation (as measured by $r$ ) for summer defined as April, May, June, July, and August. The linear regression of these data yields the equation

$$
\delta \mathrm{D}=-0.69 W_{s}-85
$$

with a correlation coeflicient of $\mathbf{- 0 . 8 2}$. The data are plotted in Figure 6. As with the Anchorage aspen, the data in Figure 6 suggest that (1) this pine incorporated predominantly summer precipitation and (2) the conditions exist for the "amount effect" to be associated with long-term, average $\delta \mathrm{D}$ values of summer rain at this locale.

The apparent ability of tree $\delta \mathrm{D}$ values to reflect annual temperature variations in some instances [e.g., Schiegl, 1974; Yapp and Epstein, 1982b] and seasonal temperature or precipitation amount in other cases (this work and that of Lawrence and White [1984]) is probably best explained in the context of the well-known seasonal variation in the isotopic composition of precipitation in temperate climates. This presumption follows from the observation that tree $\delta \mathrm{D}$ values reflect the $\delta \mathrm{D}$ values of the water passing through the tree [Epstein et al., 1976; Yapp and Epstein, 1982a; White, 1983]. Since the hydrogen in water is ultimately incorporated into cellulose as a consequence of photosynthesis, it is reasonable to expect that some average of the $\mathrm{D} / \mathrm{H}$ ratio of water passing through the tree during the growing season will be represented

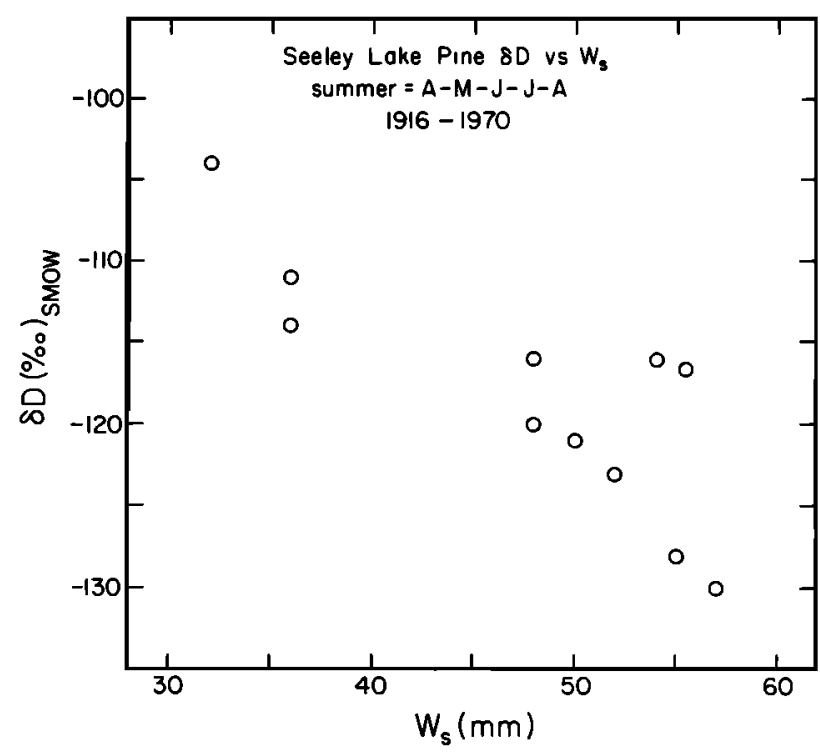

Fig. 6. Plot of Seeley Lake, British Columbia, pine tree $\delta \mathrm{D}$ values versus corresponding average monthly amounts of summer precipitation. The optimal correlation was for summer defined as April, May, June, July, and August (see text). 
in the $\mathrm{D} / \mathrm{H}$ ratio of the $\mathrm{C}-\mathrm{H}$ hydrogen of cellulose and/or cellulose precursors formed in that season. Whether or not this average $\mathrm{D} / \mathrm{H}$ value for the water passing through the tree during the growing season is representative of $\mathrm{D} / \mathrm{H}$ values of average annual precipitation or some seasonal component will depend on a number of factors: (1) is the water in soils isotopically well mixed over the course of at least 1 year; (2) if the water is not isotopically well mixed, how does it migrate through the soil, and what is the pattern of soil water uptake established by the root system; and (3) does water from the saturated zone below the water table represent a significant component of the total water passing through a tree during the growing season?

Wilde [1958] has stated that in upland soils, tree roots are not in contact with the capillary fringe of the water table. Tree roots in lowland soils, on the other hand, are said to be "influenced" by groundwater [Wilde, 1958]. White [1983] has shown that pines in upland, water-stressed growth sites use water whose $\delta \mathrm{D}$ values correspond to those of the current summer growing season precipitation. Both the Anchorage and the Fairbanks aspens are from upland sites, which probably accounts for the correlation of their $\delta \mathrm{D}$ values with summer climatic parameters. It is likely that a similar circumstance exists for the pine from the Seeley Lake area.

The model of Yapp [1982] for the relationship between precipitation $\mathrm{D} / \mathrm{H}$ ratios and precipitation intensity identifies a number of variables which can affect $D / H$ versus precipitation intensity correlations. The values of these variables need to be specified to perform calculations using this model. Calculated curves of $\delta \mathrm{D}$ versus precipitation amount for the Anchorage, Alaska, and British Columbia sites are shown in Figure 7. The values assigned to certain parameters to calculate these curves were as follows: initial condensation temperature, $5^{\circ} \mathrm{C}$; average fractionation factor, 1.116 [Majoube, 1971]; mole fraction of vapor in the vapor-condensate system, 0.80 [Ericksson, 1965]; and moist adiabatic lapse rate of $6.5^{\circ} \mathrm{C} / \mathrm{km}$. In addition, it was assumed that there is a linear correlation between precipitation intensity and precipitation amount. Tree $\delta \mathrm{D}$ values were used to assign model $\delta \mathrm{D}$ values at $W_{s}=35 \mathrm{~mm}$ and $60 \mathrm{~mm}$. The $\delta \mathrm{D}$ values for the initial vapor in cooling summer air masses at Seeley Lake, British Columbia, and Anchorage, Alaska, were calculated from extrapolation of the model curves to $W_{s}=0$. The calculated initial vapor values are about $-167 \%$ for Seeley Lake vapor and $-185 \%$ for Anchorage vapor. These calculated values assume a $22 \%$ difference between tree and precipitation $\delta \mathrm{D}$ values [Epstein et al., 1976]. This difference can be reduced by transpiration from the leaves [Yapp and Epstein, 1982a]. Thus the actual initial $\delta \mathrm{D}$ values of the vapor could be even more negative. Brown [1970] has reported an April-September, 1968 , mean summer precipitation $\delta \mathrm{D}$ value of $-133 \%$ at Prince George, British Columbia (near Seeley Lake). Such a negative value is consistent with an initial vapor $\delta \mathrm{D}$ value at least as negative as $-167 \%$. No $\mathrm{D} / \mathrm{H}$ data on Anchorage precipitation are available. Note that the model predicts a curvilinear relationship between precipitation $\mathrm{D} / \mathrm{H}$ ratios and precipitation amount, while linear correlation coefficients were initially employed to identify the relationship in the data. However, over the observed range of precipitation amount, the assumption of linearity is an adequate approximation, especially given the scatter in the data.

The number of variables in the model equations and the necessity of assigning specific "reasonable" values to most of them means that the calculated curves are not unique fits to the data. Furthermore, such model assumptions as constant

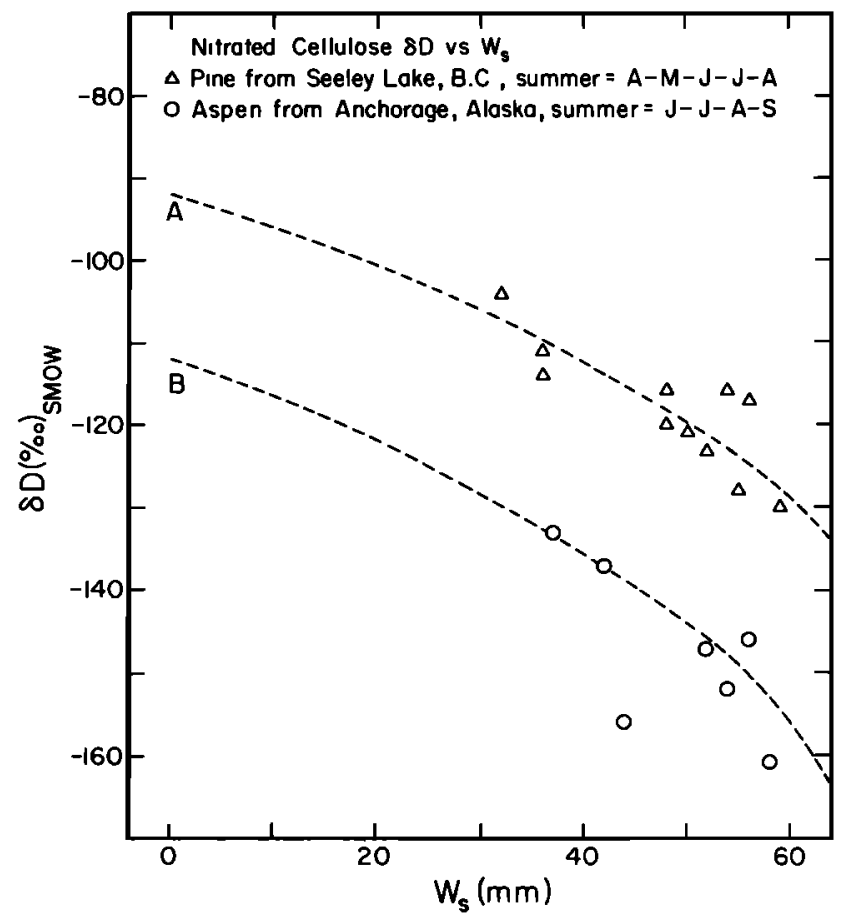

Fig. 7. Composite display of the Seeley Lake, British Columbia, pine and Anchorage aspen $\delta \mathrm{D}$ values plotted against their respective local average monthly amounts of summer precipitation $\left(W_{s}\right)$. The curves labeled $\mathbf{A}$ and $\mathbf{B}$ were calculated from the precipitation intensity model of Yapp [1982]. Assigned values of parameters used in the calculation are listed in the text.

D/H ratios for initial vapor, constant vertical velocity, constant vapor mole fraction, and constant initial condensation temperature from one 5-year sample interval to another may not be applicable here. Thus the calculated curves of Figure 7 should be treated more as vehicles for defining future research problems than as accepted explanations for correlations between tree $\delta \mathrm{D}$ and precipitation amount at these sites.

Given the young age of these three trees, it is possible that the $\delta \mathrm{D}$ versus climate relationships observed in Figures 5, 6, and 7 are those characteristic of juvenile wood. However, this would not, of itself, explain the correlations between tree $\delta \mathrm{D}$ values and summer climatic variables, since Gray and Song [1984] observed correlations between juvenile wood $\delta D$ values and annual temperatures, while Lawrence and White [1984] observed correlations between tree $\delta D$ values and amounts of summer precipitation in mature wood. Thus it would seem that growth site conditions, and possibly tree species, are the important controls on $\delta \mathrm{D}$-climate correlations. The importance of juvenile wood in such correlations is likely to be in the internal shift in tree ring isotopic records observed in progressing from juvenile to mature wood [Gray and Song, 1984].

\section{Conclusions}

Tree $\delta \mathrm{D}$ values, as recorded in tree ring sequences, do not always reflect variations in the average annual $\delta \mathrm{D}$ values of local precipitation. Alternatively, they can record changes in the $\delta \mathrm{D}$ values of seasonal components of precipitation. Local growth site conditions including upland versus lowland location, soil drainage, root geometry, and seasonal distribution of the precipitation are likely to be important in determining whether it is seasonal or annual isotopic variation that is preserved in the tree cellulose hydrogen. 
The $\delta \mathrm{D}$ values reported for tree ring sequences from the three trees in this study are correlated with variations in summer climatic conditions at each of the sites. The aspen from Fairbanks, Alaska, yielded $\delta \mathrm{D}$ data which correlated optimally with summer temperatures in Fairbanks for a summer defined as June, July, August, and September. The $\delta \mathrm{D}$ sequences from an aspen which grew near Anchorage, Alaska, and a pine located near Seeley Lake, British Columbia, appear to record variations in the amount of local summer precipitation. For the Anchorage aspen the optimal correlation was for summer defined as June, July, August, and September, while for the Seeley Lake pine, "summer" was April, May, June, July, and August. The existence of a long-term "amount effect" in the summer precipitation at Anchorage and Seeley Lake appears to have its origins in the precipitation process itself.

It is emphasized that the existence of a correlation between tree ring $\delta \mathrm{D}$ variations and some local seasonal climatic parameter for a given tree does not imply that all trees in that area will exhibit similar correlations. The specific site and growth conditions of individual trees will determine the annual versus seasonal climatic significance of $\delta \mathrm{D}$ values in trees [White, 1983]. At present, there are no internal isotopic, morphologic, or chemical criteria that can be applied to determine if the isotopic record in a tree is seasonal or annual. A search for such criteria could be of considerable importance to the successful climatic interpretation of $\mathrm{D} / \mathrm{H}$ or ${ }^{18} \mathrm{O} /{ }^{16} \mathrm{O}$ variations in ring sequences from buried fragments of ancient trees.

Acknowledgments. We thank those individuals who provided the tree samples used in this work. Their names are in the text. The paper benefited from the comments of $W$. Chameides and two anonymous reviewers. This research was supported by NSF grant ATM 8018830 . Contribution 4040 of the Division of Geological and Planetary Sciences, California Institute of Technology.

\section{REFERENCES}

Benton, G. S., and M. A. Estoque, Water-vapor transfer over the North American continent, J. Meteorol., 11, 462-477, 1954.

Brown, R. M., Distribution of hydrogen isotopes in Canadian waters, in Isotope Hydrology, pp. 3-21, International Atomic Energy Agency, Vienna, 1970.

Bryson, R. A, and F. K. Hare, The climates of North America, in World Survey of Climatology, vol. 11, edited by H. E. Landsberg. pp. 1-47, Elsevier, New York, 1974.

Burk, R. L., and M. Stuiver, Oxygen isotope ratios in trees reflect mean annual temperature and humidity, Science, 211, 1417-1419, 1981 .

Craig, H., Isotopic standards for carbon and oxygen and correction factors for mass-spectrometric analysis of carbon dioxide, Geochim Cosmochim. Acta, 12, 133-149, 1957.

Craig, H., Standard for reporting concentration of deuterium and oxygen-18 in natural water, Science, 133, 1833, 1961.

Dansgaard, W., Stable isotopes in precipitation, Tellus, 16, 436-468, 1964.

Dansgaard, W., S. J. Johnsen, H. B. Clausen, and C. C. Langway, Jr., Climatic record revealed by the Camp Century ice core, in Late Cenozoic Glacial Ages, edited by K. K. Turekian, pp. 37-56, Yale University Press, New Haven, Conn., 1971.

DeNiro, M. J., The effects of different methods of preparing cellulose nitrate on the determination of the $\mathrm{D} / \mathrm{H}$ ratios of non-exchangeable hydrogen of cellulose, Earth Planet. Sci. Lett., 54, 177-185, 1981.
Epstein, S., and T. Mayeda, Variation of $\mathrm{O}^{18}$ content of waters from natural sources, Geochim. Cosmochim. Acta, 4, 213-224, 1953.

Epstein, S., and C. J. Yapp, Climatic implications of the D/H ratio of hydrogen in C-H groups in tree cellulose, Earth Planet. Sci. Lett., 30, 252-261, 1976.

Epstein, S., R. P. Sharp, and A. J. Gow, Antarctic ice sheet: Stable isotope analyses of Byrd Station cores and interhemispheric climatic implications, Science, 168, 1570-1572, 1970.

Epstein, S., C. J. Yapp, and J. H. Hall, The determination of the D/H ratio of non-exchangeable hydrogen in cellulose extracted from aquatic and land plants, Earth Planet. Sci. Lett., 30, 241-251, 1976.

Epstein, S., P. Thompson, and C. J. Yapp, Oxygen and hydrogen isotopic ratios in plant cellulose, Science, 198, 1209-1215, 1977.

Ericksson, E., Deuterium and oxygen-18 in precipitation and other natural waters: Some theoretical considerations, Tellus, 17, 498$512,1965$.

Friedman, I., Deuterium content of natural waters and other substances, Geochim. Cosmochim. Acta, 4, 89-103, 1953.

Friedman, I., A. C. Redfield, B. Schoen, and J. Harris, The variation of the deuterium content of natural waters in the hydrologic cycle, Rev. Geophys., 2, 177-224, 1964.

Gray, J., and S. J. Song, Climatic implications of the natural variations of D/H ratios in tree ring cellulose, Earth Planet. Sci. Lett., $70,129-138,1984$.

Gray, J., and P. Thompson, Climatic information from ${ }^{18} \mathrm{O} /{ }^{16} \mathrm{O}$ ratios of cellulose in tree rings, Nature, 262, 481-482, 1976.

Hare, F. K., and J. E. Hay, The climate of Canada and Alaska, in World Survey of Climatology, vol. 11, edited by H. E. Landsberg, pp. 49-192, Elsevier, New York, 1974.

Lawrence, J. R., and J. W. C. White, Growing season precipitation from D/H ratios of eastern White Pine, Nature, 311, 558-560, 1984.

Majoube, M, Fractionnement en oxygene 18 et en deuterium entre l'eau et sa vapeur, J. Chim. Phys. Phys. Chim. Biol., 68, 1423-1436, 1971.

McKinney, C. R., J. M. McCrea, S. Epstein, H. A. Allen, and H. C. Urey, Improvements in mass spectrometers for the measurement of small differences in isotope abundance ratios, Rev. Sci. Instrum., 21, 724-730, 1950

Rozanski, K., C. Sonntag, and K. O. Munnich, Factors controlling stable isotope composition of European precipitation, Tellus, 34, $142-150,1982$

Schiegl, W. E., Climatic significance of deuterium abundance in growth rings of Picea, Nature, 251, 582-584, 1974.

Siegenthaler, U., and $\mathrm{H}$. Oeschger, Correlation of ${ }^{18} \mathrm{O}$ in precipitation with temperature and altitude, Nature, 285, 314-317, 1980.

White, J. W. C., The climatic significance of $\mathrm{D} / \mathrm{H}$ ratios in White Pine in the northeastern United States, Ph.D. thesis, Columbia Univ., New York, 1983.

Wilde, S. A., Forest Soils, Ronald Press, New York, 1958.

Yapp, C. J., A model for the relationships between precipitation D/H ratios and precipitation intensity, J. Geophys. Res., 87(C12), 9614$9620,1982$.

Yapp, C. J., and S. Epstein, Climatic implications of D/H ratios of meteoric water over North America (9500-22,000 B.P.) as inferred from ancient wood cellulose C-H hydrogen, Earth Planet. Sci. Lett., 34, 333-350, 1977.

Yapp, C. J., and S. Epstein, A reexamination of cellulose carbonbound hydrogen $\delta \mathrm{D}$ measurements and some factors affecting plant-water D/H relationships, Geochim. Cosmochim. Acta, 46, 955$965,1982 a$.

Yapp, C. J., and S. Epstein, Climatic significance of the hydrogen isotope ratios in tree cellulose, Nature, 297, 636-639, $1982 b$.

S. Epstein, Division of Geological and Planetary Sciences, California Institute of Technology, Pasadena, CA 91125.

C. J. Yapp, Department of Geology, University of New Mexico, Albuquerque, NM 87131.

(Received March 16, 1984;

revised December 11, 1984;

accepted December 19,1984.) 